\section{Rhizoctonia Rot of Swedes}

In the course of field experiments with dry rot of swedes caused by Phoma lingam (Tode) Desm., the presence of a different form of rot was observed on Magnificent and Tipperary purple topped swedes growing at East Craigs, Corstorphine. This rot was characterized by a slightly sunken, putty-coloured lesion, usually bearing closely spaced faint zone lines. It was readily distinguished from Phoma lingam rot by the absence of fructifications and the presence of a pink margin instead of a dark brown one. Such lesions were always associated with mechanical injury to the swede 'root'. The rot was comparatively shallow, dry, rather fibrous and yellowish-brown in eolour.

Plentiful white mycelium grew over the surface of cut lesions when kept under a bell jar, but no fructifications were observed. Isolations from the diseased tissues consistently yielded a strain of Rhizoctonia solani Kühn indistinguishable in culture from those recovered from sclerotia on potato tubers.

The putty-coloured, pink bordered type of lesion was confined to the purple upper part of the 'root'. On the yellow part below soil level shallow, blackishbrown, roughly circular lesions were found from which the same fungus was isolated.

Inoculation experiments were carried out with three strains of Rhizoctonia solani on mature Tipperary swede 'roots' in the laboratory: $(a)$ isolated from swede as above; $(b)$ isolated from sclerotia on the surface of a Di Vernon potato tuber ; $(c)$ isolated from dead tissue below a bruise on a Golden Wonder potato tuber.

Strain $(a)$ when inserted into cuts made with a sterile scalpel gave rise to rots identical with those observed in the field, namely, a zoned yellowish-brown lesion with pink margin on the upper parts of the 'root' and a blackish lesion with no distinctly coloured border on the yellow lower part. Pieces of agar culture of the same strain about $\frac{1}{4}$ in. square placed on the surface of uninjured 'roots' gave rise to no lesion.

Inoculations with strains $(b)$ and $(c)$ resulted in slight browning of the edges of the wound but caused no rot over a period of six weeks. Uninoculated cuts remained healthy.

About 1 per cent of the Tipperary 'roots' in the field were severely attacked by this disease.

Lauritzen ${ }^{1}$ records a similar disease of turnips in Virginia. His strain of $R$. solani apparently differed from mine in its capacity for attacking uninjured roots.

Thomas ${ }^{2}$ isolated four strains of Rhizoctonia from turnip in Holland, and Deighton ${ }^{3}$ records $R$. solani attacking turnips in Sierra Leone. Hansen ${ }^{4}$, in Norway, records infection by $R$. solani of swede seedlings in petri dishes, but I have been unable to trace any record of a swede rot in the field due to that fungus in the British Isles.

\section{R. W. G. Dennis}

Plant Pathology Service,

Seed Testing and Plant Registration Station, East Craigs, Corstorphine,

Edinburgh, 12

Dec. 16.

\footnotetext{
' Lauritzen, J. I., J. Agric. Res., 38, 93-108 (1929).

"Thomas, K. S., "Onderzoekingen over Rhizoctonia", Thesis, Utrecht (1925).

seighton, F. C., Ann. Rept. Agric. Dept. Sierra Leone, 1930, 28-31 (1931).

4 Hansen, H. P., Nordisk Jordbrugsforsk., 191-200 (1932).
}

\section{Nomenclature of Gas-Gangrene Toxins}

IN NATURE of December 7, p. 748, there is a brief note on the report of the international inquiry into the assay of gas-gangrene antitoxin (perfringens) ${ }^{\mathbf{1}}$. In this report, Prigge' ${ }^{2}$ notation is used, in which the lethal factor is described as zeta toxin and the more hæmolytic factor as alpha toxin. The use of this notation is unfortunate and likely to lead to considerable confusion. The lethal factor called zeta toxin by Prigge is identical with that which Glenny and his co-workers ${ }^{3}$ named alpha toxin in 1933, so that this usage had priority over that of Prigge by three years. During the interval, and since, a large literature has accumulated in which Glenny's nomenclature is used. It is therefore desirable to adhere to the English notation.

When in 1938 Ipsen, Sordelli and I undertook the international inquiry, it was our original intention to abide by the English method of notation, namely, to call the lethal factor alpha toxin and the more hæmolytic factor theta toxin, this last name being the one in use by Glenny for this factor in work still unpublished. For some reason unknown to me, Ipsen, who prepared our paper for publication, changed to the German notation at the last minute, and I was not aware of the change until after publication. Unfortunately, it has not been possible to communicate with Ipsen since publication, owing to the invasion of Denmark by Germany.

\section{Llewellyn Smrth.}

3 Eversley Road,

London, S.E.I9.

${ }^{2}$ Ipsen, J., Llewellyn Smith, M., and Sordelli, A., League of Nations, Bulletin of the Health Organisation, 8, 797 (1939).

' Prigge, R., Z. Immunforsch., 89.477 (1936).

${ }^{3}$ Glenny, A. T., Barr, M., Llewellyn Jones, M., Dalling, T., and Ross,

H. E., J. Path. and Bact., 37, 53 (1933).

\section{Magnetic and Thermal Properties of Crystalline Copper Sulphate at Low Temperatures}

THE principal magnetic susceptibilities of crystalline copper sulphate $\left(\mathrm{CuSO}_{4} .5 \mathrm{H}_{2} \mathrm{O}\right)$ have been measured from room temperature down to about $90^{\circ}$ K.1. From a detailed analysis of these magnetic data, Jordahl ${ }^{2}$ finds that they can be explained quantitatively on the assumption that the crystalline electric field in the neighbourhood of the $\mathrm{Cu}++$ ion in the crystal is predominantly cubic in symmetry, with a small tetragonal component superposed on it. The ground state of the $\mathrm{Cu}++$ ion is ${ }^{2} D$, and the crystalline field postulated is such that under the influence of its cubic part the energy levels split up into two sets, the lower set having a two-fold orbital degeneracy, and the upper a three-fold one, the separation between the two sets being about $18,300 \mathrm{~cm}^{-1}$; the tetragonal part of the field separates the levels of either set by about $2,550 \mathrm{~cm}^{-1}$. Each of these separated levels will have a two-fold spin degeneracy, which, being of the Kramers type, will not be removed by the crystalline field.

The type of crystalline field postulated above for explaining the magnetic data appears, from the known structure of the crystal ${ }^{3}$, to be plausible. Each copper atom in the crystal is surrounded by 6 oxygen atoms, 4 of which belong to 4 water mole- 